\title{
On the Use of NLDAS2 Weather Data for Hydrologic Modeling in the Upper Mississippi River Basin
}

\author{
Junyu Qi ${ }^{1, *}$, Qianfeng Wang ${ }^{2, *}$ and Xuesong Zhang ${ }^{1,3}$ \\ 1 Earth System Science Interdisciplinary Center, University of Maryland, College Park, MD 20740, USA; \\ xzhang14@umd.edu \\ 2 College of Environment and Resources, Fuzhou University, Fuzhou, Fujian 350116, China \\ 3 Joint Global Change Research Institute, Pacific Northwest National Laboratory and University of Maryland, \\ College Park, MD 20740, USA \\ * Correspondence: junyuqi@umd.edu (J.Q.); wangqianfeng@fzu.edu.cn (Q.W.); Tel.: +1-240-3025689 (J.Q.); \\ $+1-240-9061611$ (Q.W.)
}

Received: 10 February 2019; Accepted: 6 May 2019; Published: 8 May 2019

\begin{abstract}
Weather data are the key forces that drive hydrological processes so that their accuracy in watershed modeling is fundamentally important. For large-scale watershed modeling, weather data are either generated by using interpolation methods or derived from assimilated datasets. In the present study, we compared model performances of the Soil and Water Assessment Tool (SWAT), as driven by interpolation weather data, and NASA North American Land Data Assimilation System Phase Two (NLDAS2) weather dataset in the Upper Mississippi River Basin (UMRB). The SWAT model fed with different weather datasets were used to simulate monthly stream flow at 11 United States Geological Survey (USGS) monitoring stations in the UMRB. Model performances were evaluated based on three metrics: coefficient of determination $\left(R^{2}\right)$, Nash-Sutcliffe coefficient (NS), and percent bias $\left(\mathrm{P}_{\text {bias }}\right)$. The results show that, after calibration, the SWAT model compared well at all monitoring stations for monthly stream flow using different weather datasets indicating that the SWAT model can adequately produce long-term water yield in UMRB. The results also show that using NLDAS2 weather dataset can improve SWAT prediction of monthly stream flow with less prediction uncertainty in the UMRB. We concluded that NLDAS2 dataset could be used by the SWAT model for large-scale watersheds like UMRB as a surrogate of the interpolation weather data. Further analyses results show that NLDAS2 daily solar radiation data was about $2.5 \mathrm{MJ} \mathrm{m}^{-2}$ higher than the interpolation data. As such, the SWAT model driven by NLDAS2 dataset tended to underestimate stream flow in the UMRB due to the overestimation in evapotranspiration in uncalibrated conditions. Thus, the implication of overestimated solar radiation by NLDAS2 dataset should be considered before using NLDAS2 dataset to drive the hydrological model.
\end{abstract}

Keywords: SWAT; reanalysis climate data; stream flow; watershed modeling

\section{Introduction}

Water resources are planned and regulated on a river basin scale so that the future design and evaluation of management practices depend on the total hydrologic and biogeochemical performance of the basin instead of singular hydrologic units [1-3]. Watershed models are approaches to predict water quantity and quality of a basin accounting for complete physical, chemical, and biological processes [4]. Large-scale watersheds, such as the Upper Mississippi River Basin (UMRB), are complex systems that need physically-based and distributed watershed models to simulate their hydrological and biogeochemical functions [5]. Many watershed models are designed particularly at a large spatial scale with respect to their model structures including temporal and spatial discretization schemes, 
physical functions, and major hydrological and biogeochemical processes [6,7]. The Soil and Water Assessment Tool (SWAT) is one of these watershed models designed for simulating long-term water quantity and quality as impacted by land use and climate changes and best management practices at large-scale watersheds [6]. It is a semiphysical and semidistributed model accounting for major hydrological and biogeochemical processes significant at large spatial scale (small to large watersheds) and medium to large temporal scale (daily to monthly) [8-10]. It divides a watershed into sub-basins connected by a stream network and further delineates each sub-basin into hydrologic response units (HRUs), which consist of unique combinations of land cover, slope, and soil type [8]. The model calculates the water balance (including surface and subsurface runoff, percolation and base flow, and evapotranspiration and transmission losses), crop growth, nutrient cycling, and pesticide movement at the HRU scale [11,12]. Water flow, sediment, and nutrient loadings from each HRU in a sub-basin are summed and the resulting loadings are then routed through channels, ponds, and reservoirs to the watershed outlet $[8,13]$. It is so designed that no or minimal calibration efforts may be taken to provide reasonable simulation results at large-scale watersheds given accurate inputs including weather data, topographic and soil characteristics, and land use and management information $[8,14,15]$.

A previous study proposed a framework for developing spatial input data as detailed as possible for SWAT in the UMRB [16]. The input data include soil, land use, topography, management practices (including tile, tillage, fertilization, crop rotation, etc.), and weather information. The SWAT model was not calibrated, and it was tested directly with stream flow records from USGS monitoring gauges. The study found that the uncalibrated SWAT could satisfactorily predict the UMRB hydrologic budget. The results emphasized the importance of using accurate spatial input data for SWAT application in large-scale watersheds model. Weather data are the key forces that drive hydrological processes on land phase of global cycles so that their accuracy in watershed modeling is fundamentally important $[17,18]$. The previous study used a dataset of daily precipitation and $\mathrm{max} / \mathrm{min}$ air temperature developed by Di Luzio et al. [19] via combining daily observations from the National Climatic Data Center (NCDC) digital archives with maps from the Parameter-Elevation Regressions on Independent Slopes Model (PRISM). Then a GIS-based weather interpolation program [20] was used to aggregate the daily precipitation and max/min air temperature to sub-basins. This type of weather data interpolation methods is widely used for watersheds with sparse monitoring networks and large hydroclimatic gradients [20-23]. For large-scale watersheds, it is almost inevitably to use estimated weather data in sub-basins without monitoring data. Studies have shown that spatial precipitation estimated using different interpolation methods can be substantially different from each other [20]. In order to provide accurate spatial precipitation, it is suggested to implement multiple spatial interpolation methods and select the one with better evaluation coefficients [20]. In addition, it is time consuming and computational inefficient to process large amount of weather data for large-scale watersheds.

Another option that can be used to provide estimated weather data is usage of assimilated datasets at global gridded points [18,24-28]. There are several assimilated datasets (reanalysis), such as those provided by National Centers for Environmental Predication (NCEP)/National Center for Atmospheric Research (NCAR) and the European Centre for Medium-Range Weather Forecast (ECMWF). These datasets have relatively coarse grid size ranging from $0.125^{\circ}$ to $2.5^{\circ}$ (15 to $290 \mathrm{~km}$ ) and different periods of available data. A potential weather data source feasible for UMRB modeling is available through the NASA North American Land Data Assimilation System Phase Two (NLDAS2) [29,30]. NLDAS2 climate forcing data have assimilated multiple sources of climate observations and are widely recognized as a high resolution, spatially continuous, and comprehensive dataset that is valuable for watershed scale hydrology modeling [30]. We used the NLDAS2 dataset based on several considerations: the NLDAS2 dataset can provide all weather parameters required by SWAT including temperature, precipitation, solar radiation, relative humidity, and wind speed data; it has a smaller grid size $(15 \mathrm{~km})$ than other assimilated datasets $(\geq 15 \mathrm{~km})$; and it includes a historical coverage parallel to that of USGS monitoring records used in the UMRB. 
The objective of this study is to assess the performance of SWAT on stream flow simulation forced by NLDAS2 weather data as comparing to the model performance forced by NCDC-based interpolation weather data in the UMRB. In the present study, we intended to evaluate the applicability of NLDAS2 data used by SWAT in large-scale watersheds like the UMRB.

\section{Materials and Methods}

\subsection{Study Area}

The UMRB has a drainage area of 431,000 $\mathrm{km}^{2}$ flowing through a $2100 \mathrm{~km}$ waterway from Lake Itasca in northern Minnesota to its confluence with the Ohio River at the southern tip of Illinois (Figure 1) [16]. It includes large parts of the states of Illinois, Iowa, Minnesota, Missouri, and Wisconsin and smaller portions of Indiana, Michigan, and South Dakota (Figure 1) [5] constituting a minor portion (15 percent) of the Mississippi River Basin system. Land cover in the basin is diverse, and includes agricultural lands, forest, wetlands, lakes, prairies, and urban areas. In most parts of the UMRB, agriculture is the dominant land use and nearly $69 \%$ of total land is used for agriculture and pasture with corn, soybeans, and alfalfa as the major crops in the basin (Figure 2) [31]. Due to its large and complex landscape with intensive agricultural activities, landscape management, and widespread use of chemical fertilizers [32], UMRB is recognized as a major contributor (more than 50 percent) of nitrogen transported to the Gulf of Mexico [31]. The climate of the UMRB is subhumid continental with average monthly maximum temperature ranging from $-9.8^{\circ} \mathrm{C}$ in January in central Minnesota to $31.7^{\circ} \mathrm{C}$ in July in central Missouri, and the average annual precipitation ranges from $575 \mathrm{~mm}$ in the western part of Minnesota to $981 \mathrm{~mm}$ in the central part of Illinois [31]. About 75\% of the annual precipitation falls during corn growing season from April to October [31]. Soil type in the basin ranges from heavy, poorly drained clay soil to light, well-drained sands [33].

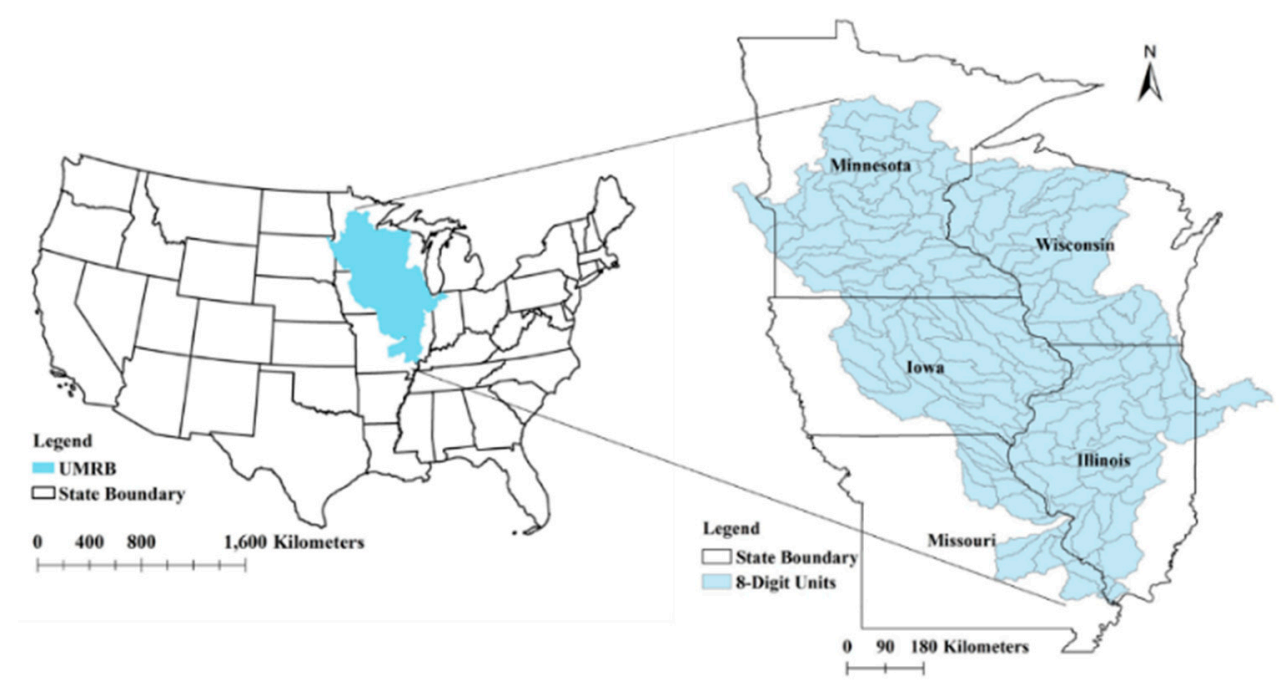

Figure 1. Location of the Upper Mississippi River Basin (UMRB) with eight-digit hydrologic unit codes (HUCs) and state boundaries. 

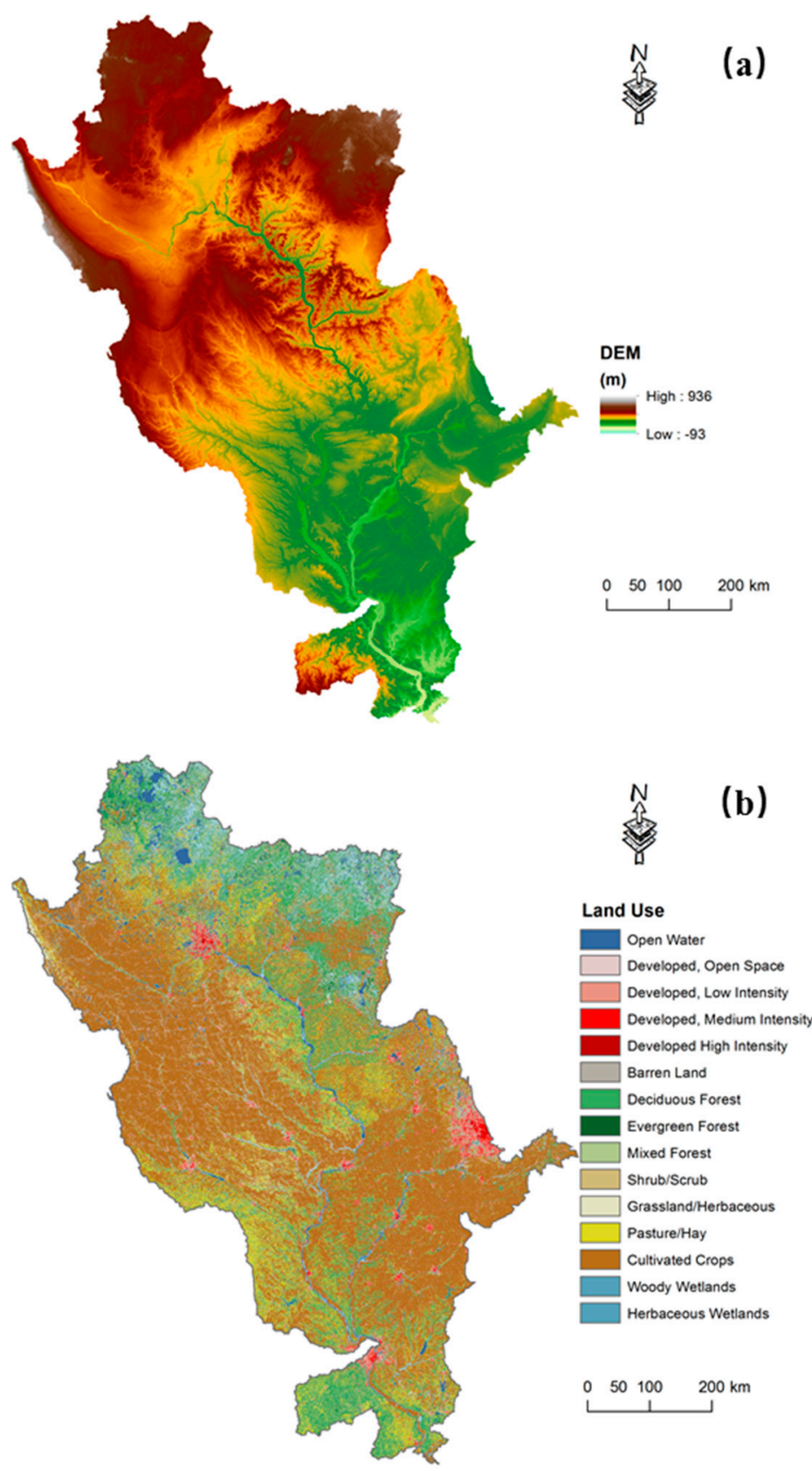

Figure 2. Digital elevation model (DEM) (a) and general land use (b) maps of the Upper Mississippi River Basin.

\subsection{SWAT Model Setup}

The SWAT model requires a variety of detailed information describing the land use, soil, and topography data of the UMRB. The UMRB was divided into 131 sub-basins according to the eight-digit United States Geological Survey (USGS) hydrologic unit codes (HUCs; Figure 1) [16]. The National Hydrography Dataset (NHD) stream dataset and a 90-m digital elevation model (DEM) were used to provide watershed configuration and topographic parameter estimation (Figure 2). A land use map was created by combing two sources of information, the Cropland Data Layer (CDL) (www.nass.usda.gov/research/Cropland/SARS1a.htm) and 2001 National Land Cover Data (NLCD2001) (Figure 2) [34]. The CDL focuses on agricultural land use with broadly defined nonagricultural land use types. Therefore, NLCD2001 was used for nonagricultural land cover information. The detailed procedure of combining both NLCD2001 and CDL can be found in Srinivasan, Zhang and Arnold [16]. 
The State Soil Geographic (STATSGO) database 1:250,000 scale soil map was used for UMRB [35]. Management practices such tile drainage, tillage, crop rotation, and fertilizer and manure application were included in the project according to Srinivasan, Zhang, and Arnold [16]. The previously established UMRB SWAT project was run with the latest versions of SWAT2012 in the present study.

\subsection{NLDAS2 Dataset}

NLDAS2 is a data assimilation system facilitated by uncoupled land surface models [30]. NLDAS2 utilized a dataset generated from gauge-based observational precipitation data, remotely sensed solar radiation, and surface meteorology reanalysis as a driver for four land surface models with a $0.125^{\circ}$ latitude-longitude resolution $(15 \mathrm{~km})$. The simulation domain covers the conterminous United States (CONUS), the southern part of Canada, and the northern portion of Mexico ( $125^{\circ}$ to $67^{\circ} \mathrm{W}, 25^{\circ}$ to $\left.53^{\circ} \mathrm{N}\right)$. Noah [36], Mosaic [37], Sacramento Soil Moisture Accounting [38], and Variable Infiltration Capacity [39] models were used to provide simulated weather parameters for various applications. NLDAS2 provides data ranging from 01-01-1979 to present. We aggregated the gridded daily values of NLDAS2 to the eight-digit sub-basins using the same procedure as in Srinivasan, Zhang and Arnold [16]. As a result, 131 weather stations, one for each sub-basin, were created to input weather data into the SWAT model.

\subsection{Three Simulation Scenarios}

The SWAT model requires daily precipitation, $\max / \mathrm{min}$ air temperature, solar radiation, relative humidity, and wind speed to simulate hydrological fluxes $[8,40]$. If the user only provides precipitation and air temperature data, daily solar radiation, relative humidity, and wind speed will be generated by the built-in WXGEN weather generator [41]. The weather generator is also used to fill-in missing data.

We used the UMRB SWAT model to simulate stream flow by considering three weather data input scenarios. The three corresponding simulations were denoted by NCDC-SWAT, NLDAS2-SWAT, and Partial-NLDAS2-SWAT (PNLDAS2-SWAT). NCDC-SWAT used daily precipitation and max/min air temperature from the NCDC-based interpolation weather data used for the previous study [16]; NLDAS2-SWAT used daily precipitation, $\mathrm{max} / \mathrm{min}$ air temperature, solar radiation, relative humidity, and wind speed from NLDAS2 data; PNLDAS2-SWAT used daily precipitation and max/min air temperature from NLDAS2 data, and solar radiation, relative humidity, and wind speed generated by the WXGEN weather generator model. PNLDAS2-SWAT was designed here to assess the impacts of precipitation and max/min temperature input data on hydrology simulation via investigating the difference between NLDAS2 data and NCDC-based interpolation data.

\subsection{Model Calibration, Sensitivity, and Uncertainty Analysis}

In the present study, the simultaneous multisite calibration procedure as described in Leta et al. [42] were used because this method can simultaneously handle the entire basin spatial variability and improve model performance. We used Sequential Uncertainty Fitting algorithm version 2 (SUFI-2) procedure in SWAT-CUP to conduct parameter sensitivity, calibration, and uncertainty analysis [43]. The global sensitivity analysis method in SWAT-CUP was used for sensitivity analysis. Parameter sensitivities were determined using the following multiple regression equation.

$$
\mathrm{g}=\alpha+\sum_{i=1}^{m} \beta_{i} \cdot b_{i}
$$

where $g$ is the objective function value, $\alpha$ and $\beta_{i}$ are regression coefficients, $b_{i}$ is the calibration parameter of the ith parameter value, and $m$ is the number of parameters considered. The Nash-Sutcliffe coefficient (NS) was used as the objective function value and Student's $t$-tests were used to identify the statistical significance of each parameter. NS was employed as the objective function because it is the most commonly used goodness-of-fit coefficient in hydrology modeling studies, and based on NS many 
model performance evaluation criteria has been established by Moriasi et al. [44]. This global sensitivity analysis approach estimates the change in the objective function (NS in the present study) resulting from changes in each parameter while all other parameters are changing. It has the advantage of being quite fast compared to similar procedures and it thus provides a relative sensitivity. The $p$-value was used to identify the relative sensitivity of parameters and a $p$-value $<0.05$ indicated a sensitive parameter in the present study.

The 95\% prediction uncertainty (95PPU) in SUFI-2 represents the combined uncertainties in model structure, parameters, and input data. The p-factor indicates the percentage of observed data falling within 95PPU band and the r-factor is the average thickness of the 95PPU bands by the standard deviation of the observed data. The r-factor can vary between 0 and infinity, while the p-factor can vary from 0 to $100 \%$ [45]. The goodness of fit and the degree to which the model accounts for uncertainties are assessed by the above two measures. Prediction uncertainty is high when the value of $\mathrm{p}$-factor is low and r-factor is high, and vice versa.

\subsection{Model Evaluation}

In the present study, we compared model performance on monthly stream flow in the three abovementioned scenarios. Figure 3 shows the USGS monitoring station locations that provided observed data used in comparisons. Table 1 shows the drainage area estimated by USGS and SWAT. Because the USGS gauge location may not always correspond to the outlet of the sub-basins, there will be some difference between the two areas. We choose a USGS monitoring station with the drainage area within $\pm 5 \%$ of the controlling areas of a sub-basin outlet (Table 1). Table 1 also provides the time period of available data for comparison of steam flow during calibration and validation for different monitoring stations. Note that the calibration/validation periods were different between monitoring stations. SWAT-CUP can be used to simultaneously calibrate multiple stations with different data range. Model performance was assessed according to three coefficients of accuracy, percent bias $\left(\mathrm{P}_{\text {bias; }}\right.$; $\%)$, coefficient of determination $\left(\mathrm{R}^{2}\right)$, and NS, given as

$$
\begin{gathered}
P_{b i a s}=100 \cdot \frac{\left(O_{a v g}-P_{a v g}\right)}{O_{a v g}} \\
N S=1-\frac{\sum_{i=1}^{n}\left(O_{i}-P_{i}\right)^{2}}{\sum_{i=1}^{n}\left(O_{i}-O_{a v g}\right)^{2}} \\
R^{2}=\left(\frac{\sum_{i=1}^{n}\left(O_{i}-O_{a v g}\right) \cdot\left(P_{i}-P_{a v g}\right)}{\left[\sum_{i=1}^{n}\left(O_{i}-O_{a v g}\right)^{2} \cdot \sum_{i=1}^{n}\left(P_{i}-P_{a v g}\right)^{2}\right]^{0.5}}\right)^{2}
\end{gathered}
$$

where $O_{i}$ and $P_{i}$ are the observed and predicted values, respectively, and $O_{a v g}$ and $P_{a v g}$ are the average of the observed and predicted values, respectively. Those coefficients are the most used statistics in evaluation of SWAT model performance on water quantity and quality simulation in the literature [16,46-49]. The $\mathrm{R}^{2}$ ranges from 0 to 1 and explains the proportion of variance in observed data, with higher values indicating less error variance; the NS is a normalized statistic and estimates the relative magnitude of the residual variance as compared to the observed (Nash and Sutcliffe 1970), and demonstrates how well the plot of observed versus simulated data fits the 1:1 line; and $\mathrm{P}_{\text {bias }}$ has the ability to indicate poor model performance and measures the average tendency of the simulated data to be larger or smaller than observed data. Low values of $\mathrm{P}_{\text {bias }}$ indicate accurate model simulation, positive values indicate model underestimation bias, and negative values indicate model overestimation bias [50]. 


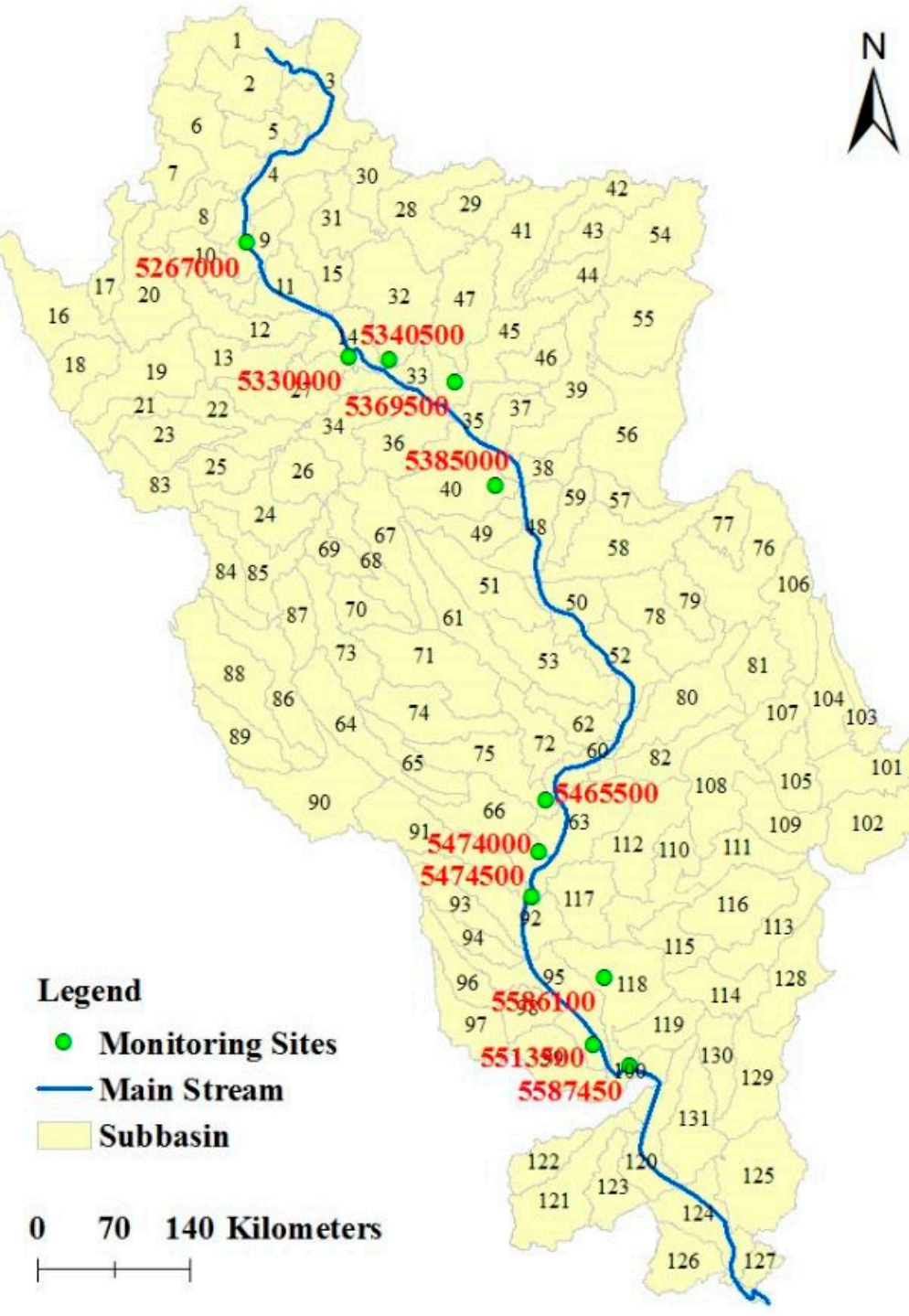

Figure 3. Location of USGS monitoring stations and sub-basins simulated by the Soil and Water Assessment Tool (SWAT). USGS stations 5267000, 5474500, 5513500, and 5587450 are located on the mean stream (see Table 1 for their corresponding sub-basin outlets).

Table 1. The drainage area of each monitoring station, the corresponding SWAT simulated drainage area, and the time period of observation data used in this study.

\begin{tabular}{cccccccc}
\hline $\begin{array}{c}\text { Sub-Basin } \\
\text { No. }\end{array}$ & USGS ID & HUC8 & $\begin{array}{c}\text { SWAT Area } \\
\mathbf{( k m}^{\mathbf{3}} \mathbf{)}\end{array}$ & $\begin{array}{c}\text { USGS Area } \\
\mathbf{( k m}^{\mathbf{3}} \mathbf{)}\end{array}$ & $\begin{array}{c}\text { SWAT Area/ } \\
\text { USGS Area }\end{array}$ & Calibration & Validation \\
\hline $\mathbf{4}$ & 5267000 & 7010104 & 30,180 & 29,696 & 1.02 & $1980-1987$ & $1988-1993$ \\
$\mathbf{2 7}$ & 5330000 & 7020012 & 43,720 & 43,126 & 1.01 & $1980-1987$ & $1988-1996$ \\
32 & 5340500 & 7030005 & 20,030 & 19,768 & 1.01 & $1980-1987$ & $1988-1996$ \\
40 & 5385000 & 7040008 & 4301 & 4250 & 1.01 & $1991-1993$ & $1994-1996$ \\
45 & 5369500 & 7050005 & 24,720 & 24,338 & 1.02 & $1991-1993$ & $1994-1996$ \\
$\mathbf{6 3}$ & 5474500 & 7080104 & 309,400 & 304,640 & 1.02 & $1980-1983$ & $1984-1987$ \\
$\mathbf{6 6}$ & 5474000 & 7080107 & 11,250 & 11,016 & 1.02 & $1980-1987$ & $1988-1995$ \\
$\mathbf{7 5}$ & 5465500 & 7080209 & 32,800 & 31,997 & 1.03 & $1980-1987$ & $1988-1995$ \\
$\mathbf{9 5}$ & 5513500 & 7110004 & 368,000 & 363,643 & 1.01 & $1991-1993$ & $1994-1996$ \\
$\mathbf{1 0 0}$ & 5587450 & 7110009 & 447,500 & 438,528 & 1.02 & $1980-1983$ & $1984-1988$ \\
$\mathbf{1 1 8}$ & 5586100 & 7140203 & 74,600 & 73,656 & 1.01 & $1991-1993$ & $1994-1996$ \\
\hline
\end{tabular}

Note: Bold numbers indicate those monitoring stations are located on the main stream. 


\section{Results and Discussion}

\subsection{Parameter Sensivity Analysis}

Table 2 lists calibrated hydrology parameters and their best simulation values in different simulation scenarios. The $p$-values for parameter sensitivity and sensitivity ranking are also included in Table 2. The sensitive parameters for monthly stream flow were SMTMP, ESCO, ALPHA_BF, GW_DELAY, and CH_K2 in scenarios of NCDC-SWAT and PNLDAS2-SWAT, while for the NLDAS2-SWAT scenario, SMTMP, CN2, SURLAG, ESCO, ALPHA_BF, and CH_K2 were the sensitive parameters. Several parameters were sensitive in all three scenarios (Table 2). SMTMP was sensitive in the three scenarios indicating that the presence of snow in the study area was affecting hydrological processes. The calibrated SMTMP value ranged from 3.23 to 3.53 greater than zero suggesting relatively large and delayed snowmelt peaks at the monthly scale during the snowmelt season in the UMRB. GW_DELAY controls the timing and magnitude of ground water discharge to streams and its value ranged from 96 to 186 days in different scenarios (Table 2), which is reasonable considering such a large-scale watershed as UMRB. ESCO affects evaporation from soils and its value was relatively low (i.e., 0.421) in scenarios of NCDC-SWAT and PNLDAS2-SWAT, while it was high (i.e., 0.937) for the NLDAS2-SWAT scenario. Lower values of ESCO indicates the model extract more of the evaporative demand from deeper soil layers. The reason for this discrepancy will be explained in Section 3.4. CH_K2 control stream flow contribution to groundwater system and it was sensitive in all scenarios showing that the bidirectional interaction between stream flow and groundwater system cannot be ignored in the UMRB. Parameters CN2 and SURLAG, which control surface runoff yield, were sensitive in scenario of NLDAS2-SWAT only (Table 2). This result indicates that using NLDAS2 weather dataset could "activate" more model parameters (making them sensitive to stream flow in the present study) which may be one of the reasons for better model performance and less prediction uncertainty in the NLDAS2-SWAT scenario than in other scenarios (as shown in following sections).

\subsection{Model Performance Evaluation}

Model performance evaluation results are shown in Tables 3 and 4 with the monthly stream flow statistics during calibration and validation, respectively, in three scenarios at 11 USGS gauges. Figure 4 shows observed vs. simulated monthly flow rate at the four gauging stations on the main of UMRB during calibration and validation. Table 1 shows available data and time periods determined for comparison during calibration and validation. During calibration, the $\mathrm{R}^{2}$ value ranged from 0.61 to 0.82 , from 0.66 to 0.86 , and from 0.64 to 0.82 ; the NS value ranged from 0.59 to 0.79 , from 0.65 to 0.84 , and from 0.61 to 0.79 ; and the $\mathrm{P}_{\text {bias }}$ (\%) value ranged from -20.6 to 10.4 , from -21.1 to 8.8 , and from -9.8 to 12.9 for scenarios of NCDC-SWAT, NLDAS2-SWAT, and PNLDAS2-SWAT, respectively (Table 3). During validation, the $\mathrm{R}^{2}$ value ranged from 0.46 to 0.92 , from 0.58 to 0.95 , and from 0.38 to 0.88 ; the NS value ranged from 0.44 to 0.85 , from 0.35 to 0.91 , and from 0.25 to 0.87 ; and the $P_{\text {bias }}(\%)$ value ranged from -8.9 to 22.5 , from -9.1 to 15.1 , and from -17.0 to 22.2 for scenarios of NCDC-SWAT, NLDAS2-SWAT, and PNLDAS2-SWAT, respectively (Table 4). 
Table 2. Calibrated hydrology parameters and their best simulation values and sensitivity ranking in three simulation scenarios.

\begin{tabular}{|c|c|c|c|c|c|c|c|c|c|}
\hline \multirow[t]{2}{*}{ Ranking } & \multicolumn{3}{|c|}{ NCDC-SWAT } & \multicolumn{3}{|c|}{ NLDAS2-SWAT } & \multicolumn{3}{|c|}{ PNLDAS2-SWAT } \\
\hline & Parameter & $p$-Value & Used & Parameter & $p$-Value & Used & Parameter & $p$-Value & Used \\
\hline 1 & V_ALPHA_BF & 0.000 & 0.2829 & V_ALPHA_BF & 0.000 & 0.2223 & V_ALPHA_BF & 0.000 & 0.2829 \\
\hline 2 & $\overline{\mathrm{V}} \_\mathrm{ESCO}$ & 0.000 & 0.421 & $\overline{\mathrm{V}} \_$ESCO & 0.000 & 0.937 & $\overline{\mathrm{V}} \_$ESCO & 0.000 & 0.421 \\
\hline 3 & V_GW_DELAY & 0.000 & 186.2 & $\mathrm{R} \_\mathrm{CN} 2$ & 0.000 & -0.0345 & V_GW_DELAY & 0.000 & 186.2 \\
\hline 4 & $\overline{\mathrm{V}} \mathrm{CH} \mathrm{K}_{2}$ & 0.000 & 84.1 & $\mathrm{~V}$ SMTMP & 0.000 & 3.23 & $\mathrm{~V}$ CH_K2 & 0.000 & 84.1 \\
\hline 5 & V_SMTMP & 0.000 & 3.53 & $\mathrm{~V}$ _CH_K2 & 0.000 & 34.5 & V_SMTMP & 0.013 & 3.53 \\
\hline 6 & V_SURLAG & 0.102 & 0.505 & V_SURLAG & 0.033 & 1.995 & V_SURLAG & 0.080 & 0.505 \\
\hline 7 & $\bar{R} \_\mathrm{CN} 2$ & 0.552 & -0.0465 & V_EW_DELAY & 0.184 & 96.2 & V_SFTMP & 0.212 & 2.23 \\
\hline 8 & V__SFTMP & 0.584 & 2.23 & V__SFTMP & 0.321 & -3.21 & R_SOL_K & 0.803 & -0.1345 \\
\hline 9 & R_SOL_K & 0.922 & -0.1345 & R_SOL_K & 0.946 & 0.0475 & $\mathrm{R} \_\mathrm{CN} 2$ & 0.896 & -0.0465 \\
\hline
\end{tabular}

Notes: R and V stand for relative change (\%) and replace value, respectively. Bold $p$-value indicates the sensitive parameter ( $p$-value $<0.05)$. ALPHA_BF: baseflow alpha factor (day); GW_DELAY: groundwater delay days (day); CN2: initial SCS CN II value; SURLAG: surface runoff lag time (day); ESCO: soil evaporation compensation factor; SOL_K: soil hydraulic conductivity $\left(\mathrm{mm} \mathrm{hr}^{-1}\right)$; $\mathrm{CH} \_\mathrm{K} 2$ : effective hydraulic conductivity of stream $\left(\mathrm{mm} \mathrm{hr}^{-1}\right)$; SFTMP: snowfall temperature $\left({ }^{\circ} \mathrm{C}\right)$; SMTMP: snow melt base temperature $\left({ }^{\circ} \mathrm{C}\right)$. 
Table 3. Model performance on monthly stream flow at 11 monitoring stations in three scenarios during calibration.

\begin{tabular}{cccccccccc}
\hline \multirow{2}{*}{ Sub-Basin } & \multicolumn{3}{c}{ NCDC-SWAT } & \multicolumn{3}{c}{ NLDAS2-SWAT } & \multicolumn{3}{c}{ PNLDAS2-SWAT } \\
\cline { 2 - 10 } & $\mathbf{R}^{\mathbf{2}}$ & $\mathbf{N S}$ & $\mathbf{P}_{\text {bias }}$ & $\mathbf{R}^{\mathbf{2}}$ & $\mathbf{N S}$ & $\mathbf{P}_{\text {bias }}$ & $\mathbf{R}^{\mathbf{2}}$ & $\mathbf{N S}$ & $\mathbf{P}_{\text {bias }}$ \\
\hline 4 & 0.73 & 0.71 & -6.7 & 0.76 & 0.65 & -5.9 & 0.76 & 0.75 & 4.9 \\
27 & 0.76 & 0.73 & -6.2 & 0.78 & 0.68 & -12.2 & 0.74 & 0.71 & 4.7 \\
32 & 0.76 & 0.73 & 0.4 & 0.75 & 0.72 & 8.8 & 0.78 & 0.72 & 12.3 \\
40 & 0.81 & 0.70 & -20.6 & 0.82 & 0.70 & -21.1 & 0.76 & 0.73 & -9.8 \\
45 & 0.61 & 0.59 & -6.2 & 0.66 & 0.65 & -2.5 & 0.64 & 0.61 & -4.1 \\
63 & 0.77 & 0.76 & -3.6 & 0.80 & 0.80 & -0.7 & 0.79 & 0.78 & 4.0 \\
66 & 0.75 & 0.74 & -3.0 & 0.75 & 0.74 & -3.8 & 0.72 & 0.72 & 1.4 \\
75 & 0.74 & 0.72 & 6.2 & 0.80 & 0.79 & 3.7 & 0.78 & 0.73 & 12.9 \\
95 & 0.79 & 0.78 & 6.5 & 0.84 & 0.84 & -0.9 & 0.81 & 0.79 & 9.6 \\
100 & 0.80 & 0.79 & 2.7 & 0.83 & 0.83 & 2.5 & 0.79 & 0.76 & 9.2 \\
118 & 0.82 & 0.77 & 10.4 & 0.86 & 0.81 & 5.1 & 0.82 & 0.75 & 10.6 \\
\hline
\end{tabular}

Note: Shaded statistics for NLDAS2-SWAT and PNLDAS2-SWAT indicate their values are greater than or equal to the corresponding values of NCDC-SWAT.

Table 4. Model performance on monthly stream flow at 11 monitoring stations in three scenarios during validation.

\begin{tabular}{cccccccccc}
\hline \multirow{2}{*}{ Sub-Basin } & \multicolumn{3}{c}{ NCDC-SWAT } & \multicolumn{3}{c}{ NLDAS2-SWAT } & \multicolumn{3}{c}{ PNLDAS2-SWAT } \\
\cline { 2 - 10 } & $\mathbf{R}^{\mathbf{2}}$ & $\mathbf{N S}$ & $\mathbf{P}_{\text {bias }}$ & $\mathbf{R}^{\mathbf{2}}$ & $\mathbf{N S}$ & $\mathbf{P}_{\text {bias }}$ & $\mathbf{R}^{\mathbf{2}}$ & $\mathbf{N S}$ & $\mathbf{P}_{\text {bias }}$ \\
\hline 4 & 0.57 & 0.54 & 4.4 & 0.63 & 0.48 & -9.1 & 0.62 & 0.54 & 11.4 \\
27 & 0.85 & 0.78 & 22.5 & 0.81 & 0.80 & -0.3 & 0.81 & 0.76 & 22.2 \\
32 & 0.67 & 0.64 & 8.9 & 0.66 & 0.65 & 1.1 & 0.71 & 0.68 & 11.5 \\
40 & 0.46 & 0.44 & -2.0 & 0.58 & 0.35 & 15.1 & 0.38 & 0.25 & 10.1 \\
45 & 0.83 & 0.81 & -1.3 & 0.79 & 0.65 & -9.1 & 0.76 & 0.50 & -17.0 \\
63 & 0.78 & 0.75 & -8.9 & 0.79 & 0.79 & -2.2 & 0.82 & 0.81 & 0.6 \\
66 & 0.86 & 0.83 & 5.3 & 0.87 & 0.86 & -7.8 & 0.82 & 0.82 & -2.8 \\
75 & 0.85 & 0.80 & 13.1 & 0.88 & 0.86 & 5.0 & 0.85 & 0.81 & 12.3 \\
95 & 0.80 & 0.71 & 2.4 & 0.77 & 0.74 & -6.7 & 0.79 & 0.76 & -4.7 \\
100 & 0.86 & 0.85 & -5.5 & 0.87 & 0.87 & 1.9 & 0.88 & 0.87 & 3.9 \\
118 & 0.92 & 0.83 & 13.0 & 0.95 & 0.91 & 5.3 & 0.88 & 0.78 & 15.3 \\
\hline
\end{tabular}

Note: Shaded statistics for NLDAS2-SWAT and PNLDAS2-SWAT indicate their values are greater than or equal to the corresponding values of NCDC-SWAT.

The SWAT model performed "satisfactorily" for all monitoring stations in three scenarios based on model performance evaluation criteria during calibration and validation (Tables 3 and 4). Simulated monthly flow rate matched well observation in three simulation scenarios at the four selected monitoring stations (Figure 4). Furthermore, the SWAT model was able to depict seasonal variations of stream flow at different stations in three scenarios. The results indicate that the SWAT model can adequately produce long-term water yield in the UMRB with different weather forcing dataset. In Tables 3 and 4, shaded statistics for NLDAS2-SWAT and PNLDAS2-SWAT indicate that their values are greater than or equal to the corresponding values of NCDC-SWAT. In the NLDAS2-SWAT scenario, the SWAT model improved $\mathrm{R}^{2}$ and NS for stream flow at most stations during both calibration and validation (Tables 3 and 4), while no distinct improvement were observed in the PLDAS2-SWAT scenario. The improvement can be detected from Figure 4 where the SWAT model in the NLDAS2-SWAT scenario depicted high flows more closely. It is worth noting that improvement in $\mathrm{R}^{2}, \mathrm{NS}$, and $\mathrm{P}_{\text {bias }}$ tended to occur in southern parts of the UMRB implying that the simplified snow accumulation and melt algorithm within the SWAT model may offset the advantage of using NLDAS2 weather dataset. In general, these results 
show that using NLDAS2 weather data can improve SWAT prediction of stream flow at large scale watersheds like UMRB.
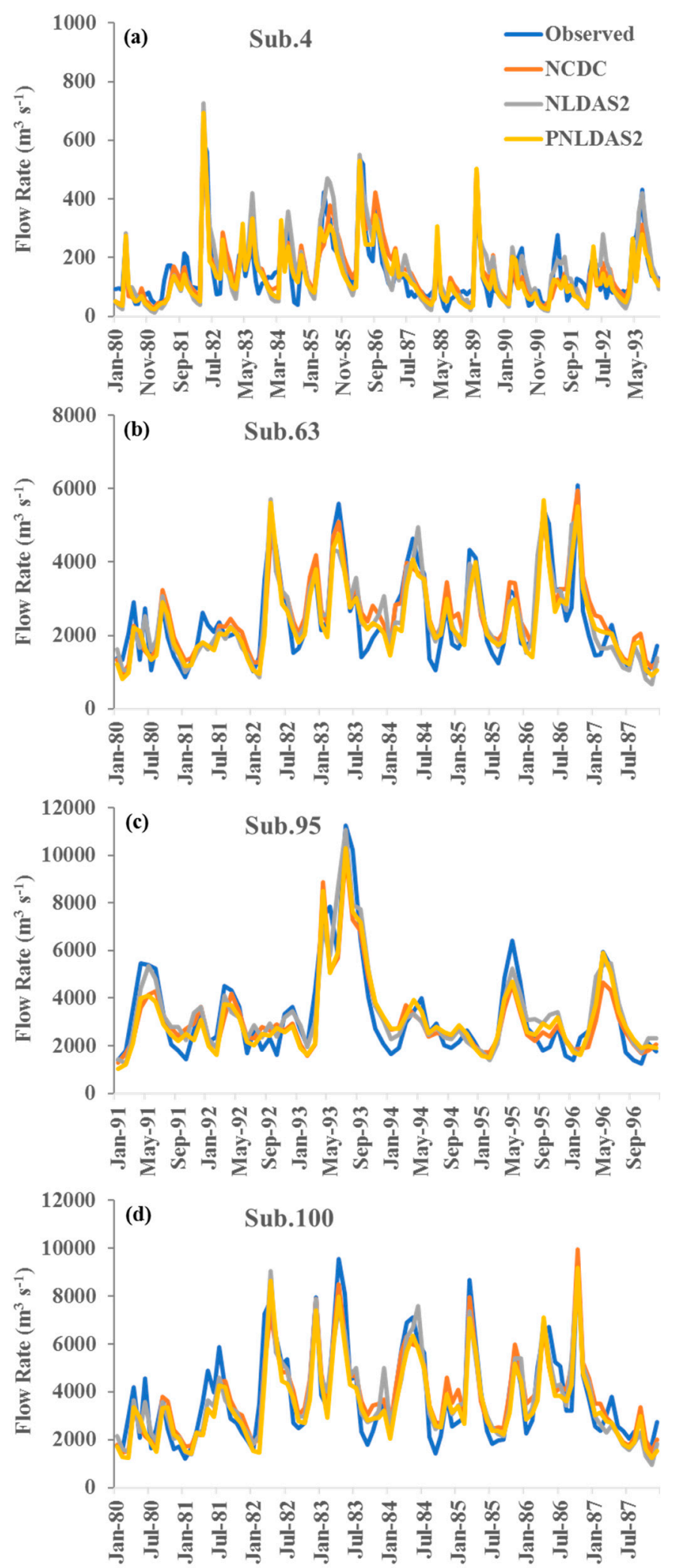

Figure 4. Observed vs. simulated monthly flow rate at the four gauging stations on the main of UMRB during calibration and validation (i.e., USGS 5267000, 5474500, 5513500, and 5587450; see Table 1 for their corresponding sub-basin outlets and evaluation periods). 


\subsection{Model Uncertainty Analysis}

Table 5 lists the p-factor and $\mathrm{r}$-factor for simulated $95 \%$ confidence intervals for monthly stream flow at 11 monitoring stations in the three simulation scenarios. The p-factor values showed that the $95 \%$ bands capture $94-100 \%, 91-100 \%$, and $97-100 \%$ of the observed monthly stream flow for scenarios NCDC-SWAT, NLDAS2-SWAT, and PNLDAS2-SWAT, respectively, at 11 monitoring stations. The r-factor values were ranged from 1.23 to 2.73 , from 1.06 to 2.36 , and from 1.29 to 2.69 for scenarios NCDC-SWAT, NLDAS2-SWAT, and PNLDAS2-SWAT, respectively, at 11 monitoring stations (Table 5). p-factor $>0.7$ and $r$-factor $<\sim 1$ (e.g., 1.5) indicates that a model had acceptable prediction uncertainty [51]. Apparently the three scenarios had satisfactory $\mathrm{p}$-factor results while $\mathrm{r}$-factor results were not satisfying for all 11 monitoring stations. There is a trade-off between $\mathrm{p}$-factor and $\mathrm{r}$-factor that a larger $\mathrm{p}$-factor can be achieved at the expense of a larger $r$-factor. In order to detect the difference of model uncertainty in the three scenarios, we plotted scatter plot of $p$-factor vs. $r$-factor for the three scenarios as shown in Figure 5. The plot more clearly shows that the values of r-factor in the NLDAS2-SWAT scenario were less than those of other two scenarios while the values of $\mathrm{p}$-factor were close to each other in different scenarios. This result suggests that, in general, NLDAS2 data improved SWAT simulation of monthly stream flow with less prediction uncertainty in the large-scale watershed like UMRB.

Table 5. $\mathrm{p}$-factor and $\mathrm{r}$-factor for different sub-basins in three simulation scenarios.

\begin{tabular}{ccccccc}
\hline \multirow{2}{*}{ Sub-Basin } & \multicolumn{2}{c}{ NCDC-SWAT } & \multicolumn{2}{c}{ NLDAS2-SWAT } & \multicolumn{2}{c}{ PNLDAS2-SWAT } \\
\cline { 2 - 6 } & p-Factor & r-Factor & p-Factor & r-Factor & p-Factor & r-Factor \\
\hline 4 & 0.99 & 2.57 & 0.91 & 1.86 & 1.00 & 2.52 \\
27 & 0.97 & 1.56 & 0.93 & 1.31 & 1.00 & 1.58 \\
32 & 0.94 & 1.86 & 0.92 & 1.57 & 0.98 & 1.82 \\
40 & 0.96 & 2.23 & 0.99 & 1.97 & 0.99 & 2.25 \\
45 & 0.95 & 2.40 & 1.00 & 2.36 & 0.98 & 2.59 \\
63 & 1.00 & 2.73 & 0.97 & 2.23 & 1.00 & 2.69 \\
66 & 0.95 & 1.23 & 0.90 & 1.06 & 0.97 & 1.29 \\
75 & 0.97 & 1.37 & 0.92 & 1.18 & 0.99 & 1.41 \\
95 & 1.00 & 1.98 & 0.96 & 1.87 & 1.00 & 2.11 \\
100 & 1.00 & 2.32 & 0.92 & 1.92 & 1.00 & 2.28 \\
118 & 1.00 & 1.81 & 0.91 & 1.65 & 0.99 & 1.85 \\
\hline
\end{tabular}

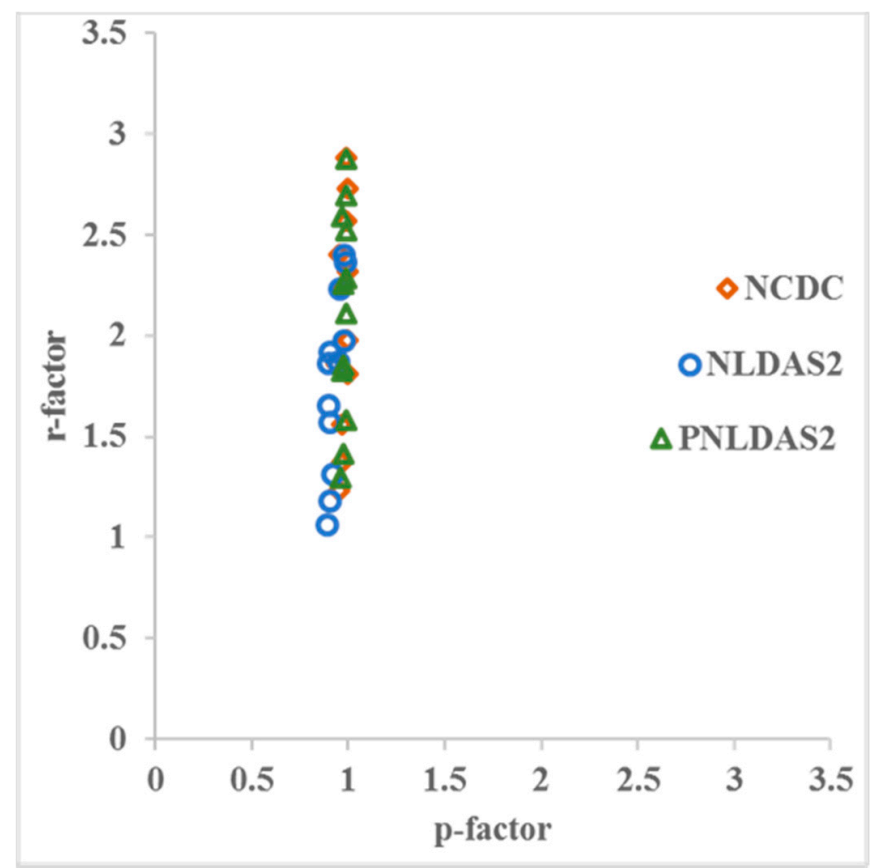

Figure 5. Scatter plot for $\mathrm{p}$-factor and $\mathrm{r}$-factor for different sub-basin in three simulation scenarios. 


\subsection{Weather Data Impacts on Stream Flow Simulation}

In the present study, we first examined the model performance using uncalibrated UMRB SWAT in the three simulation scenarios. The purpose of this comparison was to investigate model responses to different weather inputs without the influence of parameter calibration. We found that the uncalibrated SWAT model tended to overestimate stream flow in the NCDC-SWAT scenario (similar results were reported in Gao et al. [52]), while in the NLDAS2-SWAT scenario, the uncalibrated SWAT model had the tendency to underestimate stream flow on monthly scale. To understand the reason for those biases, we summarized annual average precipitation, daily air temperature, and daily solar radiation used in three scenarios compared with annual average water yield, evapotranspiration, and soil water generated over the UMRB for the simulation period as shown in Figure 6. In addition, we also summarized average annual water balance components (in $\mathrm{mm}$ ) simulated in three scenarios at the UMRB as shown in Table 6. Apparently, there was not much differences in annual precipitation (only $8 \mathrm{~mm}$ on average) between NCDC and NLDAS2 data (Table 6 and Figure 6a). However, NLDAS2 data had slightly higher daily air temperatures than NCDC data with an average difference of $0.68^{\circ} \mathrm{C}$ for the simulation period (Figure $6 \mathrm{c}$ ). Notice that the NLDAS2 data has much higher daily solar radiation than NCDC data with a difference of $2.5 \mathrm{MJ} \mathrm{m}^{-2} \mathrm{~d}^{-1}$. The reason for the underestimation of stream flow (or water yield) in the UMRB was mainly due to the overestimation in evapotranspiration caused by overestimation of solar radiation by using NLDAS2 data. We exclude the temperature impacts because the SWAT model used the same air temperature input in both scenarios of NLDAS2-SWAT and PNLDAS2-SWAT, but the differences in water balance components of the UMRB (including surface runoff, lateral flow, baseflow, percolation, tile flow, soil water, and ET) between PNLDAS2-SWAT and NCDC-SWAT were smaller than the differences between NLDAS2-SWAT and NCDC-SWAT. Thus, combining precipitation and temperature data from NLDAS2 with solar radiation generated by SWAT built-in weather generator can be a feasible option for large-scale watershed modeling in studies using the uncalibrated SWAT model.

Table 6 also lists water balance components simulated by calibrated SWAT models in three scenarios. Compared with the results generated by the uncalibrated SWAT models, there were less difference between different scenarios for each water balance component (Table 6). The results indicate that model calibration would to some extent diminish the influence of different weather data inputs and converge the magnitude of simulated water balance components to a narrower range. This is because the SWAT model was calibrated against the same observed stream flow data at multiple monitoring stations in the UMRB for the three simulation scenarios. The differences between three simulation scenarios for different water balance components, though relatively small, was the result of different weather data inputs. 
Table 6. Average annual water balance components (in $\mathrm{mm}$ ) over the UMRB simulated using the uncalibrated and calibrated SWAT model in three scenarios.

\begin{tabular}{|c|c|c|c|c|c|c|c|c|c|c|c|}
\hline Model & Scenario & Participation & Surface Runoff & Lateral Flow & Baseflow & Percolation & Tile Flow & Soil Water & ET & PET & Water Yield \\
\hline \multirow[t]{3}{*}{ Uncali. } & NCDC-SWAT & 863 & 126 & 13 & 145 & 146 & 34 & 228 & 545 & 792 & 303 \\
\hline & NLDAS2-SWAT & 871 & 113 & 10 & 91 & 91 & 20 & 206 & 641 & 996 & 223 \\
\hline & PNLDAS2-SWAT & 871 & 133 & 12 & 134 & 135 & 31 & 221 & 560 & 838 & 297 \\
\hline \multirow[t]{3}{*}{ Cali. } & NCDC-SWAT & 863 & 95 & 11 & 127 & 120 & 29 & 210 & 608 & 780 & 247 \\
\hline & NLDAS2-SWAT & 871 & 98 & 12 & 127 & 124 & 30 & 219 & 612 & 996 & 254 \\
\hline & PNLDAS2-SWAT & 871 & 94 & 11 & 118 & 111 & 26 & 202 & 630 & 830 & 235 \\
\hline
\end{tabular}



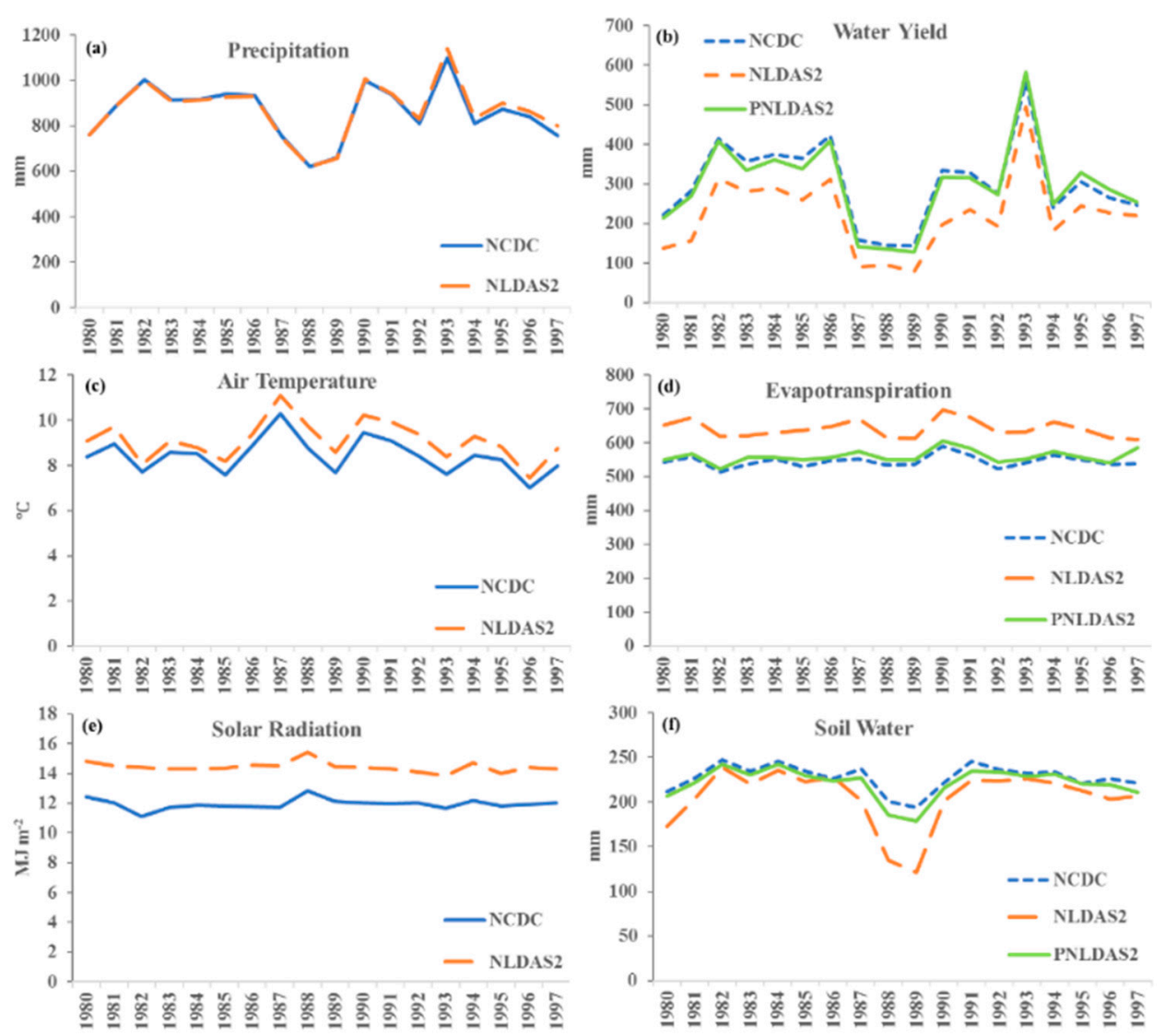

Figure 6. Annual average precipitation, daily air temperature, and daily solar radiation used in three scenarios compared with generated annual average water yield, evapotranspiration, and soil water over the UMRB using the uncalibrated SWAT model.

\section{Conclusions}

The present study compared interpolation weather data and NASA North American Land Data Assimilation System Phase Two (NLDAS2) weather data used in SWAT application at a large-scale watershed-the Upper Mississippi River Basin (UMRB). Interpolation weather data were derived based on National Climatic Data Center (NCDC) archives. Three scenarios with different weather data input were considered, including NCDC-SWAT, NLDAS2-SWAT, and Partial-NLDAS2-SWAT (PNLDAS2-SWAT). NCDC-SWAT used daily precipitation and $\mathrm{max} / \mathrm{min}$ air temperature from the NCDC-based interpolation weather data; NLDAS2-SWAT used daily precipitation, $\mathrm{max} / \mathrm{min}$ air temperature, solar radiation, relative humidity, and wind speed from NLDAS2 data; and PNLDAS2-SWAT used daily precipitation and max/min air temperature from NLDAS2 data, and solar radiation, relative humidity, and wind speed generated by the WXGEN weather generator within SWAT. In the three scenarios, the SWAT model was used to simulate monthly stream flow at 11 USGS monitoring stations in the UMRB. Model performances were evaluated according to three statistics: coefficient of determination $\left(\mathrm{R}^{2}\right)$, Nash-Sutcliffe coefficient $(\mathrm{NS})$, and percent bias $\left(\mathrm{P}_{\text {bias }}\right)$, on the monthly temporal scale. We further conducted parameter sensitivity and model uncertainty analyses using the Sequential Uncertainty Fitting algorithm version 2 (SUFI-2) procedure in SWAT-CUP. The results show that the SWAT model compared well at all monitoring stations for stream flow in three scenarios indicating that the SWAT model can adequately produce long-term water yield in UMRB. The results also show that using NLDAS2 weather data can improved SWAT prediction of stream flow with less prediction uncertainty in the UMRB. We concluded that NLDAS2 data can be used by the SWAT model for large-scale watersheds like UMRB as a surrogate of interpolation weather data. 
We also conducted a study using uncalibrated SWAT model to simulate monthly stream flow in the UMRB with the three scenarios. The comparison results indicated that NLDAS2 data have higher daily solar radiation than interpolation weather data (the difference is $\sim 2.5 \mathrm{MJ} \mathrm{m}^{-2} \mathrm{~d}^{-1}$ ) and, as a result, the SWAT model underestimated stream flow in the UMRB due to the overestimation of evapotranspiration in the scenario of NLDAS2-SWAT. The implication of the overestimated solar radiation by NLDAS2 should be fully considered when using the uncalibrated SWAT model. We pointed that combining precipitation and temperature from NLDAS2 data with solar radiation generated by SWAT built-in weather generator can be a feasible option for large-scale watershed modeling.

Author Contributions: Conceptualization, X.Z., and J.Q.; Methodology, J.Q.; Software, J.Q.; Validation, Q.W.; Formal Analysis, J.Q.; Investigation, X.Z.; Resources, X.Z.; Data Curation, Q.W.; Writing-Original Draft Preparation, J.Q.; Writing-Review and Editing, Q.W. and J.Q.; Visualization, J.Q.; Supervision, X.Z.; Project Administration, X.Z.; Funding Acquisition, X.Z.

Funding: The funding support for this project was provided by NASA (NNX17AE66G and NNH13ZDA001N), USDA (2017-67003-26485), and NSF INFEWS (1639327).

Conflicts of Interest: The authors declare no conflicts of interest

\section{References}

1. Parmele, L.H. Errors in output of hydrologic models due to errors in input potential evapotranspiration. Water Resour. Res. 1972, 8, 348-359. [CrossRef]

2. Xia, J.; Chen, J.; Weng, J.; Yu, L.; Qi, J.; Liao, Q. Vulnerability of water resources and its spatial heterogeneity in Haihe River Basin, China. Chin. Geogr. Sci. 2014, 24, 525-539. [CrossRef]

3. Sun, L.; Yang, F.; Wang, J.; Fang, H.; Qi, J. Impacts of forest types on soil C, N and DOC loss in runoff in the laterite hilly region of southern China. Environ. Earth Sci. 2015, 74, 1391-1402.

4. Clark, M.P.; Fan, Y.; Lawrence, D.M.; Adam, J.C.; Bolster, D.; Gochis, D.J.; Hooper, R.P.; Kumar, M.; Leung, L.R.; Mackay, D.S. Improving the representation of hydrologic processes in Earth System Models. Water Resour. Res. 2015, 51, 5929-5956. [CrossRef]

5. Arnold, J.G.; Muttiah, R.S.; Srinivasan, R.; Allen, P.M. Regional estimation of base flow and groundwater recharge in the Upper Mississippi river basin. J. Hydrol. 2000, 227, 21-40. [CrossRef]

6. Arnold, J.G.; Srinivasan, R.; Muttiah, R.S.; Williams, J.R. Large area hydrologic modeling and assessment part I: Model development. JAWRA J. Am. Water Resour. Assoc. 1998, 34, 73-89. [CrossRef]

7. Gassman, P.W.; Reyes, M.R.; Green, C.H.; Arnold, J.G. The soil and water assessment tool: historical development, applications, and future research directions. Trans. ASABE 2007, 50, 1211-1250. [CrossRef]

8. Neitsch, S.L.; Williams, J.R.; Arnold, J.G.; Kiniry, J.R. Soil and Water Assessment Tool Theoretical Documentation Version 2009; Grassland, Soil and Water Research Service: Temple, TX, USA, 2011.

9. Zhang, C.; Li, S.; Qi, J.; Xing, Z.; Meng, F. Assessing impacts of riparian buffer zones on sediment and nutrient loadings into streams at watershed scale using an integrated REMM-SWAT model. Hydrol. Process. 2017, 31, 916-924. [CrossRef]

10. Qi, J.; Li, S.; Li, Q.; Xing, Z.; Bourque, C.P.-A.; Meng, F.-R. A new soil-temperature module for SWAT application in regions with seasonal snow cover. J. Hydrol. 2016, 538, 863-877. [CrossRef]

11. Qi, J.; Li, S.; Yang, Q.; Xing, Z.; Meng, F.-R. SWAT Setup with Long-term detailed landuse and management records and modification for a micro-watershed influenced by freeze-thaw cycles. Water Resour. Manag. 2017, 31, 3953-3974. [CrossRef]

12. Li, Q.; Qi, J.; Xing, Z.; Li, S.; Jiang, Y.; Danielescu, S.; Zhu, H.; Wei, X.; Meng, F.-R. An approach for assessing impact of land use and biophysical conditions across landscape on recharge rate and nitrogen loading of groundwater. Agric. Ecosyst. Environ. 2014, 196, 114-124. [CrossRef]

13. Qi, J.; Zhang, X.; McCarty, G.W.; Sadeghi, A.M.; Cosh, M.H.; Zeng, X.; Gao, F.; Daughtry, C.S.; Huang, C.; Lang, M.W. Assessing the performance of a physically-based soil moisture module integrated within the Soil and Water Assessment Tool. Environ. Model. Softw. 2018, 109, 329-341. [CrossRef]

14. Vrugt, J.A.; Ter Braak, C.J.; Clark, M.P.; Hyman, J.M.; Robinson, B.A. Treatment of input uncertainty in hydrologic modeling: Doing hydrology backward with Markov chain Monte Carlo simulation. Water Resour. Res. 2008, 44. [CrossRef] 
15. Qi, J.; Li, S.; Bourque, C.P.; Xing, Z.; Fan-Rui, M. Developing a decision support tool for assessing land use change and BMPs in ungauged watersheds based on decision rules provided by SWAT simulation. Hydrol. Earth Syst. Sci. 2018, 22, 3789-3806. [CrossRef]

16. Srinivasan, R.; Zhang, X.; Arnold, J. SWAT ungauged: hydrological budget and crop yield predictions in the Upper Mississippi River Basin. Trans. ASABE 2010, 53, 1533-1546. [CrossRef]

17. Obled, C.; Wendling, J.; Beven, K. The sensitivity of hydrological models to spatial rainfall patterns: an evaluation using observed data. J. Hydrol. 1994, 159, 305-333. [CrossRef]

18. Dile, Y.T.; Srinivasan, R. Evaluation of CFSR climate data for hydrologic prediction in data-scarce watersheds: an application in the Blue Nile River Basin. JAWRA J. Am. Water Resour. Assoc. 2014, 50, 1226-1241. [CrossRef]

19. Di Luzio, M.; Johnson, G.L.; Daly, C.; Eischeid, J.K.; Arnold, J.G. Constructing retrospective gridded daily precipitation and temperature datasets for the conterminous United States. J. Appl. Meteorol. Clim. 2008, 47, 475-497. [CrossRef]

20. Zhang, X.; Srinivasan, R. GIS-Based spatial precipitation estimation: a comparison of geostatistical approaches. JAWRA J. Am. Water Resour. Assoc. 2009, 45, 894-906. [CrossRef]

21. Kyriakidis, P.C.; Kim, J.; Miller, N.L. Geostatistical mapping of precipitation from rain gauge data using atmospheric and terrain characteristics. J. Appl. Meteorol. 2001, 40, 1855-1877. [CrossRef]

22. Piper, S.C.; Stewart, E.F. A gridded global data set of daily temperature and precipitation for terrestrial biospheric modeling. Glob. Biogeochem. Cycles 1996, 10, 757-782. [CrossRef]

23. Hijmans, R.J.; Cameron, S.E.; Parra, J.L.; Jones, P.G.; Jarvis, A. Very high resolution interpolated climate surfaces for global land areas. Int. J. Clim. 2005, 25, 1965-1978. [CrossRef]

24. Kalnay, E.; Kanamitsu, M.; Kistler, R.; Collins, W.; Deaven, D.; Gandin, L.; Iredell, M.; Saha, S.; White, G.; Woollen, J. The NCEP/NCAR 40-year reanalysis project. Bull. Am. Meteorol. Soc. 1996, 77, 437-472. [CrossRef]

25. Kouwen, N.; Danard, M.; Bingeman, A.; Luo, W.; Seglenieks, F.R.; Soulis, E.D. Case study: watershed modeling with distributed weather model data. J. Hydrol. Eng. 2005, 10, 23-38. [CrossRef]

26. Najafi, M.R.; Moradkhani, H.; Piechota, T.C. Ensemble streamflow prediction: climate signal weighting methods vs. climate forecast system reanalysis. J. Hydrol. 2012, 442, 105-116. [CrossRef]

27. Smith, R.A.; Kummerow, C.D. A comparison of in situ, reanalysis, and satellite water budgets over the Upper Colorado River Basin. J. Hydrometeorol. 2013, 14, 888-905. [CrossRef]

28. Yin, J.; Zhan, X. Impact of bias-correction methods on effectiveness of assimilating SMAP soil moisture data into NCEP global forecast system using the ensemble Kalman filter. IEEE Geosci. Remote Sens. Lett. 2018, 15, 659-663. [CrossRef]

29. Mitchell, K.E.; Lohmann, D.; Houser, P.R.; Wood, E.F.; Schaake, J.C.; Robock, A.; Cosgrove, B.A.; Sheffield, J.; Duan, Q.; Luo, L. The multi-institution North American Land Data Assimilation System (NLDAS): Utilizing multiple GCIP products and partners in a continental distributed hydrological modeling system. J. Geophys. Res. Atmos. 2004, 109. [CrossRef]

30. Xia, Y.; Mitchell, K.; Ek, M.; Sheffield, J.; Cosgrove, B.; Wood, E.; Luo, L.; Alonge, C.; Wei, H.; Meng, J. Continental-scale water and energy flux analysis and validation for the North American Land Data Assimilation System project phase 2 (NLDAS-2): 1. Intercomparison and application of model products. J. Geophys. Res. Atmos. 2012, 117. [CrossRef]

31. Wu, J.; Tanaka, K. Reducing nitrogen runoff from the upper Mississippi River basin to control hypoxia in the Gulf of Mexico: easements or taxes? Marine Resour. Econ. 2005, 20, 121-144. [CrossRef]

32. Jha, M.; Gassman, P.W.; Secchi, S.; Gu, R.; Arnold, J. Effect of watershed subdivision on swat flow, sediment, and nutrient predictions. JAWRA J. Am. Water Resour. Assoc. 2004, 40, 811-825. [CrossRef]

33. Qi, J.; Zhang, X.; Wang, Q. Improving hydrological simulation in the Upper Mississippi River Basin through enhanced freeze-thaw cycle representation. J. Hydrol. 2019, 571, 605-618. [CrossRef]

34. Homer, C.; Huang, C.; Yang, L.; Wylie, B.; Coan, M. Development of a 2001 national land-cover database for the United States. Photogramm. Eng. Remote Sens. 2004, 70, 829-840. [CrossRef]

35. USDA-NRCS. State Soil Geographic (STATSGO) Database Misc. Pub. 1492; USDA-NRCS National Soil Survey Center: Lincoln, NE, USA, 1995.

36. Ek, M.; Mitchell, K.; Lin, Y.; Rogers, E.; Grunmann, P.; Koren, V.; Gayno, G.; Tarpley, J. Implementation of Noah land surface model advances in the National Centers for Environmental Prediction operational mesoscale Eta model. J. Geophys. Res. Atmos. 2003, 108. [CrossRef] 
37. Koster, R.D.; Suarez, M.J. Energy and Water Balance Calculations in the Mosaic LSM; National Aeronautics and Space Administration, Goddard Space Flight Center, Laboratory for Atmospheres, Data Assimilation Office; Laboratory for Hydrospheric Processes: Washington, DC, USA, 1996.

38. Burnash, R.; Ferral, R.; McGuire, R. A Generalized Streamflow Simulation System-Conceptual Modeling for Digital Computers; US National Weather Service, State of California, Dept. of Water Resources: Sacramento, CA, USA, 1973.

39. Liang, X.; Lettenmaier, D.P.; Wood, E.F.; Burges, S.J. A simple hydrologically based model of land surface water and energy fluxes for general circulation models. J. Geophys. Res. Atmos. 1994, 99, 14415-14428. [CrossRef]

40. Qi, J.; Li, S.; Jamieson, R.; Hebb, D.; Xing, Z.; Meng, F.-R. Modifying SWAT with an energy balance module to simulate snowmelt for maritime regions. Environ. Model. Softw. 2017, 93, 146-160. [CrossRef]

41. Sharpley, A.N.; Williams, J.R. EPIC-Erosion/Productivity Impact Calculator: 1, Model Documentation; USDA-ARS. Technical Bulletin. USDA. Agricultural Research Service: Beltsville, MA, USA, 1990; p. 127.

42. Leta, O.T.; van Griensven, A.; Bauwens, W. Effect of single and multisite calibration techniques on the parameter estimation, performance, and output of a SWAT model of a spatially heterogeneous catchment. J. Hydrol. Eng. 2016, 22, 05016036. [CrossRef]

43. Abbaspour, K.; Vejdani, M.; Haghighat, S. SWAT-CUP calibration and uncertainty programs for SWAT. In Proceedings of the MODSIM 2007 International Congress on Modelling and Simulation, Modelling and Simulation Society of Australia and New Zealand, Christchurch, New Zealand, 10-13 December 2007.

44. Moriasi, D.N.; Arnold, J.G.; Van Liew, M.W.; Bingner, R.L.; Harmel, R.D.; Veith, T.L. Model evaluation guidelines for systematic quantification of accuracy in watershed simulations. Trans. ASABE 2007, 50, 885-900. [CrossRef]

45. Singh, A.; Imtiyaz, M.; Isaac, R.; Denis, D. Assessing the performance and uncertainty analysis of the SWAT and RBNN models for simulation of sediment yield in the Nagwa watershed, India. Hydrol. Sci. J. 2014, 59, 351-364. [CrossRef]

46. Qi, J.; Li, S.; Li, Q.; Xing, Z.; Bourque, C.P.-A.; Meng, F.-R. Assessing an enhanced version of SWAT on water quantity and quality simulation in regions with seasonal snow cover. Water Resour. Manag. 2016, 30, 5021-5037. [CrossRef]

47. Qi, J.; Zhang, X.; Cosh, M.H. Modeling soil temperature in a temperate region: A comparison between empirical and physically based methods in SWAT. Ecol. Eng. 2019, 129, 134-143. [CrossRef]

48. Arnold, J.G.; Moriasi, D.N.; Gassman, P.W.; Abbaspour, K.C.; White, M.J.; Srinivasan, R.; Santhi, C.; Harmel, R.; Van Griensven, A.; Van Liew, M.W. SWAT: Model use, calibration, and validation. Trans. ASABE 2012, 55, 1491-1508. [CrossRef]

49. Zhang, X.; Srinivasan, R.; Hao, F. Predicting hydrologic response to climate change in the Luohe River basin using the SWAT model. Trans. ASABE 2007, 50, 901-910. [CrossRef]

50. Gupta, H.V.; Sorooshian, S.; Yapo, P.O. Status of automatic calibration for hydrologic models: Comparison with multilevel expert calibration. J. Hydrol. Eng. 1999, 4, 135-143. [CrossRef]

51. Abbaspour, K.C. SWAT-CUP 2012: SWAT Calibration and Uncertainty Programs-A User Manual; Eawag: Dübendorf, Switzerland, 2013.

52. Gao, J.; Sheshukov, A.Y.; Yen, H.; White, M.J. Impacts of alternative climate information on hydrologic processes with SWAT: A comparison of NCDC, PRISM and NEXRAD datasets. Catena 2017, 156, 353-364. [CrossRef]

(C) 2019 by the authors. Licensee MDPI, Basel, Switzerland. This article is an open access article distributed under the terms and conditions of the Creative Commons Attribution (CC BY) license (http://creativecommons.org/licenses/by/4.0/). 